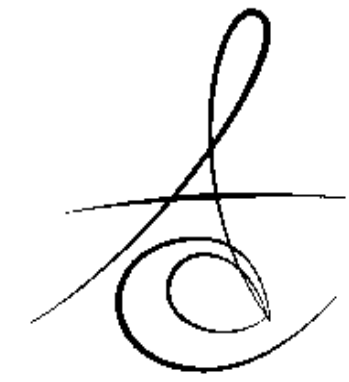

Makale Kodu/Article code: 1557

Makale Gönderilme tarihi: 24.02.2014

Kabul Tarihi: 16.06.2014

\section{İMPLANT UYGULAMALARI İÇİN KRET KORUMA TEKNİKLERİ}

RIDGE PRESERVATION TEHCHNIQUES FOR IMPLANT THERAPY

\author{
Yrd. Doç. Dr.Merve ÇAKIR*
}

\section{ÖZET}

Diş çekimi sonrasında meydana gelen kemik rezorpsiyonu implant yerleştirilmesi için uygun olmayan kret yapısına neden olmaktadır. Kret korunması, çekim sonrası meydana gelen değişiklikleri sınırlamaya yönelik bir tekniktir. Bu derlemenin amacı çekim sonrası meydana gelen değişiklikleri göstermek ve kret korunması için kullanılabilecek teknikleri değerlendirmektir.

Anahtar kelimeler: alveoler kret korunması, implant, çekim soketinin iyileşmesi, kemik rezorpsiyonu

\section{İMPLANT UYGULAMALARI İÇİN KRET KORUMA TEKNİKLERİ}

Başarılı implant tedavisi için gerekli olan ön koşullar; implantın osseointegrasyonu, ideal implant pozisyonu ve uygun sert ve yumuşak doku konturlarıdır ${ }^{1}$. İmplant uygulamalarının sonuçları artık sadece implantın ömrüyle değil aynı zamanda implantın uzun dönem estetik ve fonksiyonel başarısıyla da ölçülmektedir $^{2,3}$.

Yumuşak ve sert doku arasındaki ilişki implant hastalarındaki estetik sonuçlar için önemlidir. Yumuşak doku konturu, altındaki kemiğin anatomisine bağlıdır. İmplantın üç boyutlu pozisyonlandırımasının yanlış yapılması restoratif tedavide zorluğa neden olan uygun olmayan restorasyon-implant uyumuyla sonuçlanabilir ${ }^{2-4}$.

Estetik sonuçlar, implantın üç boyutlu olarak doğru yerleştirilmesinin yanı sıra implant bölgesinde uygun olan kemik miktarından da etkilenmektedir ${ }^{3}$. Diş çekiminden sonra alveoler krette çekim sebebine ve çekim bölgesine göre değişen miktarlarda rezorptif değişiklikler görüldüğü bilinmektedir ${ }^{1,3,5,6}$. Bu

\section{ABSTRACT}

Bone resorption following tooth extraction may lead to inappropriate ridge structure. Ridge preservation is a technique which limits amount of the bone loss after extraction. The purpose of this article is to show changes tooth extraction and evaluate techniques of ridge preservation.

Key words: ridge preservation, implant, extraction socket healing, bone resorption

değişiklikler kret boyutlarında azalmaya neden olmaktadır. Bu durum yetersiz kemik hacmine ve dental implant yerleştirilmesi için uygunsuz kret yapısına neden olabilmektedir ${ }^{3}$. Bu derlemenin amacl; diş çekimi sonrasında alveoler krette meydana gelen değişiklikleri ve uygun implant tedavisi için bu değişikliklerle nasıl başa çıkılabileceğini tartışmak ve minimuma indirip implant uygulamasına uygun hale getirebilmek için kullanılabilecek teknikleri gözden geçirmektir (Tablo 1). Kret koruma yöntemlerinden bahsetmeden önce diş çekimi sonrasında sokette meydana gelen değişiklikleri anlayabilmek için çekim soketinin iyileşmesinden bahsetmemiz gerekmektedir.

\section{ÇEKİM SOKETİNİN İYİLEŞMESİ}

Çekim soketinin iyileşmesi; soket içinde kemik oluşumuna sebep olan internal değişiklikler ve alveoler kretin genişliğinde ve uzunluğunda kayıplara neden

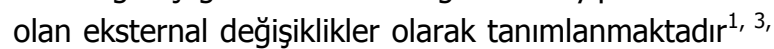
6. Çekim soketinin iyileşmesi sırasında oluşan olaylar: ikan pıhtısının oluşumu ve matürasyonu, ii- pıhtının ortadan kalkması için fibroblastların infiltrasyonu ve iiikemik doku oluşumunu sağlayan geçici matriksin oluşumudur. Çekim soketinin iyileşmesi sırasında

*Gazi Üniversitesi Diş Hekimliği Fakültesi Ağız-Diş Çene Cerrahisi Anabilim Dalı

** İstanbul Yeni Yüzyıl Üniversitesi Diş Hekimliği Fakültesi Ağız-Diş ve Çene Cerrahisi Anabilim Dalı 
görülen olaylarla uzun kemiklerin fraktürlerinin iyileşmesi sırasında görülen olaylar arasında benzerlikler mevcuttur? ${ }^{7}$.

\section{İnternal Değişiklikler}

Dişin soketten uzaklaştırılmasının ardından hemoraji oluşmaktadır ${ }^{1}$. Soket, çeşitli damarlardan gelen proteinleri ve hasarlı hücreleri içeren kanla dolar $^{8}$. Bu hemorojiyi takiben bu hücreler fibrin ağı oluşumunu sağlayan bir seri olayları başlatır, bunun yanında platelletler ilk 24 saatte tüm soketi kaplayan bir kan pıhtısı oluştururlar ${ }^{1,8}$. Bu durum granülasyon dokusu oluşturmak için hücrelerin toplanmasını uyaran bir inflamatuar reaksiyondur ${ }^{1}$. Pıhtı, fiziksel bir matriks gibi davranır ${ }^{8}$. Çekimden sonraki 48-72 saat içinde granülasyon dokusu özellikle soket tabanından pıhtı içine infiltre olmaya başladığı için pıhtı bozulmaya başlar (fibrinolisis) ${ }^{1}{ }^{8}$. Soketin koronal kısmında granülasyon dokusu, ağız içinde enfeksiyoz materyaller bulunduğu için bu kısımda bir bariyer oluşturup soketin daha apikaldeki kısımlarını korur ${ }^{7}$. Dört günde soket çevresi boyunca epitel prolifere olur ve immatür bağ doku görülür. Yedi gün sonra granülasyon dokusu tamamen infiltre olur ve pıhtı ile yer değiştirir ${ }^{1}$. Birinci haftanın sonunda vasküler ağ oluşur ve iki hafta sonunda çekim soketinin marjinal kısmı damardan ve inflamatuar hücrelerden zengin genç bağ dokusu ile kaplanır ${ }^{8}$. Bu aşamada osteoid, kalsifiye olmamış kemik spekülleri şeklinde soketin tabanında belirginleşir. Sonraki 2-3 haftanın ardından (çekimden 3-4 hafta sonra) osteoid soket tabanından koronale doğru mineralize olmaya başlar. Bu olay çekimden 6 hafta sonra tüm soketi kaplayacak olan reepitelizasyon ile birlikte devam eder. Maksimum radyografik yoğunlukla birlikte kemiğin dolması 100 gün içinde gerçekleşir. Kemiğin hiçbir zaman komşu dişlerin seviyesine kadar rejenere olmayacağı yani $\% 100$ lük bir kemik dolumu olmayacağı unutulmamalıdır ${ }^{1,3}$.

Soketin boyutu soket iyileşmesini etkilemektedir; geniş soketlerde dar soketlere nazaran defekti onarmak için daha fazla zamana gerek vardır. Tek köklü dişlere nazaran çok köklü dişlerin soketlerinde kemik oluşumu daha uzun zaman almaktadır. Horizontal kemik kaybı olan dişlerin soketleri daha çabuk iyileşmektedir ${ }^{1,3,6}$.

\section{Eksternal Değişiklikler}

Çekim sonrası ilk sekiz haftada kret tepesinde lingual ve bukkal duvarlarda rezorpsiyonla sonuçlanan osteoklastik aktivite göze çarpar. Bukkal duvarda daha fazla yükseklik kaybı olurken bunun yanında bukkal ve lingual duvarların her ikisinde birden horizontal kayıp görülür. Bu önemli bir bulgudur; çünkü optimal implant estetiği için bukkal kemiğin genişliğinin ve yüksekliğinin yeterli olması önemlidir. Bukkal kemikteki kayıp, kötü ve yetersiz estetiğe neden olmaktadır ${ }^{1,3,9}$.

\section{Boyutsal Değişiklikler}

Çekim soketinin eksternal bukkal ve lingual duvarlarında görülen rezorpsiyon kretin boyutlarında değişiklikle sonuçlanmaktadır ${ }^{1}$. Yapılan çalışmalarda; soket iyileşmesi sırasında, oklüzalden bakınca rezidüel kret tepesi linguale doğru kayarken, lateralden bakıldığında ise; komşu dişlere göre krette bir yassılaşma çukurlaşma görüldüğü bildirilmektedir ${ }^{8-10}$. Son zamanlarda yapılan çalışmalar, kret genişliğinde kret yüksekliğinden çok daha fazla azalma görüldüğünü belirtmektedir ${ }^{1,11,12}$. Rezorpsiyondaki bu çeşitliliğin nedeni olarak; anatomik, metabolik, fonksiyonel, protetik, genetik ve iyatrojenik faktörler gösterilmiştir ${ }^{1}$, ${ }^{8}$ Bukkal ve lingual duvarlardaki rezorpsiyon birbiriyle çakışan iki fazda gerçekleşmektedir. Faz 1 sırasında, periodontal ligament liflerinin bağlandığı kemik (bundle bone) fonksiyonunu kaybettiği için rezorbe olur ve süngerimsi kemikle yer değiştirir. Bukkal kemik tepesi periodontal ligament liflerinin bağlandığı kemik ile kaplı olduğundan bu rezorpsiyon bukkalde vertikal kemik kaybına neden olur. Faz 2; bukkal ve lingual kemik duvarlarının dış yüzlerinde olan kemik rezorpsiyonunu içermektedir. Diş çekimi sırasında flep kaldırılması sonucunda kemiklerin kan damarları zarar görür, kemiklerin damarsal beslenmesi azaldığı için osteositler nekroze olur ve sonucunda kemik duvarlarının mineralize dokusu nekroze olur. Bukkal kemik lingual kemikten ince olduğu için bu horizontal rezorpsiyon bukkal kemikte vertikal kemik kaybına da neden olabilir. Flep kaldırımadığı halde diş çekimi sonrasında faz 2'de görülen kemik rezorpsiyonları görülebilir. Bunun nedenleri; i- çekim sahasında fonksiyon eksikliğine adaptasyon, ii- diş eksikliğinde genetik olarak kret geometrisinin gerekliliklerini karşılamak için doku uyumlanması olabilir9.

Çekim sonrası en çok etkilenen alanlara bakıldığında alveoler rezorpsiyonun her iki çenede de bukkal tarafta daha fazla olduğunu belirtilmektedir ${ }^{8,9}$. Alt ve üst dişleri çevreleyen alveoler kemiğin labial anatomisine bakıldığı zaman bu durum kolaylıkla anlaşılabilmektedir: fasiyal alveol kenarları; ince, genelde kortikal, bıçak sırtı şeklinde ve kırılgandır ${ }^{8}$.

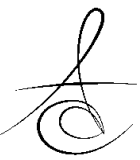


Araujo ve ark. ${ }^{13}$ bukkal ve lingual kemiklerdeki rezorpsiyon farkını yukarıdaki nedenlere ek olarak; periodontal ligament liflerinin bağlandığı kemiğin erken kaybına ve ek yüzey rezorpsiyonlarının geniş lingual kemik duvarından daha çok hassas bukkal kemikte etkili olmasına da bağlamaktadırlar. Periodon- tal ligament liflerinin bağlandığı kemik, lingual kısımdaki kemiğe nazaran dişlerin bukkal kemik duvarlarının marjinal kısmının daha büyük bir parçasını oluşturmaktadır.

Rezidüel krette görülen rezorpsiyonun derecesi maksilla ve mandibulanın her ikisinde de çekimden sonra geçen zamanla yakından ilişkilidir $^{8}$. En hızlı değişiklikler ilk 6 ay ve 2 yıllık dönemi kapsayan çekim sonrası erken periyotta görülmektedir. Damarsal beslenmesi daha iyi olduğu için maksillada mandibuladan daha hızı bir iyileşme görülmektedir ki bu da mandibulada maksilladan 4 kat daha hızlı rezorpsiyon görülmesini açıklamaktadır ${ }^{1,8}$.

Schropp ve ark. ${ }^{6}$ yaptıkları bir çalışmada tek diş çekiminin ardından görülen rezorpsiyon modelini araştırmışlardır. Çalışmada 12 aylık dönemde tek diş çekimi sonrasında alveoldeki kemik formasyonu ve alveoler proçesteki kontur değişiklikleri incelenmiştir. Çalışmaya göre alveoler genişlikte \%50'lik bir azalma görülmüştür ve bu azalmanın üçte ikisi ilk üç ayda görülmüştür, kayıp ortalama 5-7 mm'dir ve tüm bölgelerde benzerdir. Diş çekimi sonrası kret genişliği ortalama $12 \mathrm{~mm}$ iken, 12 ay sonra 5,9 mm olarak ölçülmüştür. Kemik yüksekliğindeki değişiklikler çok azdır (ortalama $1 \mathrm{~mm}$ ). Rejenere olan kemik yüksekliği hiçbir zaman komşu dişlerin koronal seviyesine ulaşamamıştır. Kemik yüzeyi apikale doğru eğimlidir. Araştırmacılar, kemikteki bu kayıp önlenebilirse bunun bir avantaj olacağını belirtmişlerdir.

Çekim sonrası iyileşme olaylarındaki anlayışa göre, implant yerleştirilmesinin 6 ay veya daha uzun süre ertelenmesi gerekiyorsa diş çekimi sonrası kret rezorpsiyonunun engellenmesi önemlidir. İmplant yerleştirilmesi kemik kaybında ve şu koşullarda ertelenebilir:

- Soket duvarları ve soket alanındaki sınırlı kemik yüksekliği mevcudiyetinde (periodontal harabiyetli ve büyük apikal defektli dişlerin çekimi sonrası),

- Soketin morfolojisi implantı ideal pozisyonda yerleştirilmesini engelliyorsa,

- Büyümenin devam ettiği genç hastalarda,

- Hasta implant tedavisini karşılayamadığında ve
Sistemik sağlık problemleri nedeniyle implant yerleştirilmesin kontrendike olduğu durumlar.

Eğer kret boyutları korunabilirse bu durum; ilerdeki ogmentasyon ve cerrahi işlem gereksinimini azaltmaktadır ve gelecekteki implant cerrahisini kolaylaştırmaktadır ${ }^{1,3}$.

\section{KRET KORUNMASI}

Kret korunması, çekim sırasında veya çekimi takiben oluşan eksternal kret rezorpsiyonunu minimalize etmek ve soketteki kemik formasyonunu maksimuma çıkarmak için yapılan işlemlerin tümüne verilen isimdir ${ }^{1}$.

Kret korunması, implant yerleştirilmesi diş çekiminden 6-8 haftadan daha uzun süre sonra yapılacaksa göz önünde bulundurulmalıdır. Eğer çekim sonrası immediat implant yerleştirilecekse veya çekim sonrası 6-8 hafta içinde implant yerleştirilmesi planlanıyorsa kret koruma prosedürlerinin uygulanmasının yararı çok az olmaktadır. İmplant operasyonu yakın bir zamanda planlanmıyorsa hastanın gelecekte implant yaptırma olasılığının devam edebilmesi için stratejik olarak önemli alanlara kret koruma prosedürlerinin uygulanması değerlendirilmelidir ${ }^{1}$.

Kret koruma prosedürlerinin özel endikasyonları;

- Bukkal kemiğin 1,5-2 mm'den ince olduğu alanlar (hemen hemen her zaman anterior bölge) ve zarar görmüş veya bir veya daha fazla soket duvarı kaybı olan alanlar (bu alanlarda iyileşme sırasında klinik olarak önemli miktarda kemik kaybı olur ve başarılı implant tedavisi için zorluk oluştururlar),

- Anatomik yapılara zarar verme riski olan kemik miktarının çok önemli olduğu alanlar (maksilla posterior bölgede maksiller sinüs bölgesi ve mandibula posterior bölgede inferior alveoler sinir bölgesi),

- Yüksek dudak hattı veya ince dişeti yapısına sahip hastalar gibi dişeti çekilmesine daha yatkın olan yüksek estetik beklentisi olan hastalar,

- Çok fazla dişin çekileceği, ilerdeki restorasyonlar için kret korunmasının önemli olduğu hastalardır ${ }^{1,3}$.

Kret korunmasının kontrendikasyonları ise;

- Akut enfeksiyon varlığı,

- Soket iyileşmesi tek başına düzgün kret morfolojisiyle sonuçlanabileceği durumlar,

- Kemik hacmi elde etmenin önemli olmadığı durumlar ve

- Sistemik kontrendikasyonlardır ${ }^{1,3}$. 
Bazı kret koruma teknikleri yönlendirilmiş kemik/doku rejenerasyonu prensiplerine dayanmaktadır ${ }^{13}$. Kret korunması için kullanılan materyaller yönlendirilmiş kemik rejenerasyonu veya yönlendirilmiş doku rejenerasyonu için kullanılan materyallerle aynıdır ${ }^{3}$.

Yapılan araştırmalara göre kret korunması için birçok yöntem uygulanmaktadır. Bu yöntemlerin bazıları;

- Çekim soketi içine greft yerleştirilip, membranla örtüldükten sonra tam ya da parsiyel olarak fleple kapatılması,

- Sokete greft yerleştirilip membransız bir şekilde koronale kaydırılan fleplerle ya da rotasyonel fleplerle greftin kapatılması,

- Membranın sokete tek başına yerleştirilip tam ya da parsiyel olarak soketin fleplerle kapatılması,

- Tek başına greft yerleştirilmesi,

- Greftlenmiş soketin tek başına membranla kapatılması,

- Sadece greftle kaplayıp kret korunması,

- Greft yerleştirip kollajen doku örtüsüyle kaplanması,

- Rezorbe olan tampon yerleştirip yumuşak dokuyla kaplamak,

- PRP kullanılması

- Minimal travmatik diş çekimi,

- Immediat implant yerleştirilmesidir ${ }^{1,3,12-17 .}$

Kret korunması sırasında kullanılacak uygun materyalin seçimi bazı soruların cevaplarına göre yapılmalıdır. İlk göz önünde bulundurulması gereken implant yerleştirilmesinin zamanıdır. 'İmplant 6-8 hafta içinde yerleştirilecek mi veya implant yerleştirilmesi bu zamandan sonrasına mı ertelenecek?'. İmplant yerleştirilmesi ertelenecekse sonraki soru; 'sokette implantın primer stabilitesini etkileyecek kadar önemli zarar var mı ve greft gerekiyor mu?' olmalıdır. Bu gibi durumlarda sadece yeni kemik oluşumuna değil aynı zamanda mümkün olduğunca mevcut kemiğin korunmasına da dikkat edilmelidir. Bu durumda yavaş rezorbe olan ve sonuç olarak yeni kemik oluşturan bir materyal (inorganik sığır kemiği, biyoaktif cam, bifazik kalsiyum sülfat gibi) tercih edilir. Eğer implant 6-8 hafta içinde yerleştirilecekse; 'greft gerekli mi?' sorusu sorulmalıdır. Soket duvarları sağlamsa ve önemli bir rezorpsiyon beklenmiyorsa cevap negatif olmalıdır. Eğer soket zarar görmüşse, soket duvarlarından biri kaybedildiyse kretin çökmesi hızlı rezorbe olan materyallerle (kollajen tampon, kalsiyum sülfat gibi) minimalize edilmelidir ${ }^{1}$.

\section{Minimal Travma ile Diş Çekimi}

Diş çekimi kaçınılmaz olarak travmatik bir işlem olmasına rağmen uygun aletlerle minimal kuvvet uygulanması sert ve yumuşak dokuya verilen zararın kısıtlanması için tavsiye edilmektedir. İyi elevatörler ve periotomlarla dişler periodontal ligamentlerinden ayrılarak davyelerle yavaşça soketlerden çıkarılabilir. Çok köklü dişlerde önce kronu ayırıp daha sonra kökleri ayırarak almak bölgeyi daha az travmaya uğratmaktadır. İmplant uygulamalarındaki artış tüm diş çekimlerinin minimal travma ile yapılması gerekliliğini düşündürmektedir. Diş çekimi sırasında implant planlanmıyorsa bile daha sonra implant yapılabileceği göz önüne alınarak diş çekimi yapılmalıdır ${ }^{1}$

\section{Sadece Greft Kullanımı}

Greftleme sonrası kemik iyileşmesi ve ardından yeni kemik formasyonu osteogenesis, osteoindüksiyon ve/veya osteokondüksiyon aracılığıyla meydana gelmektedir ${ }^{18,19}$. Otojen kemik greftleri, kemik rejenerasyonu prosedürlerinde 'altın standart' olarak kabul edilmektedirler ${ }^{20-22}$. Ancak otojen kemik greftlerinin; kısıtlı miktarda elde edilebilmesi, kısmi rezorpsiyon yatkınlığı, ek cerrahi işlem gerektirmesi ve verici sahada morbidite riski gibi dezavantajları bulunmaktadır $^{20,22-25}$. Otojen greftlerin bu dezavantajları, araştırmacıları alternatif greft materyalleri araştırmaya yönlendirmiştir ${ }^{26}$. Allogreftler, zenogreftler ve alloplastik materyaller alternatif olarak kullanılmaktadır ${ }^{20}$.

Alveoler kemik atrofisi diş kaybının sık görülen bir sonucu olduğu ve çoğu durumda çeşitli kemik greftleme materyallerinin pozitif sonuçlar gösterdiği belirtilmektedir ${ }^{18}$. Bu nedenle alveoler kemik atrofisini azaltmak amacıyla çekim soketlerine; demineralize kuru dondurulmuş kemik allogreftleri (DFDBA), deproteinize sığır kemiği mineralleri (DBBM) otojen kemik greftleri, biyoaktif cam ve kalsiyum sülfat gibi çeşitli greft materyalleri yerleştirilmiştir ${ }^{1,3,5,14,18,27}$. Bu greft materyalleri, sadece osteojenik hücrelerin osteokondüksiyonuna yardım etmek için yer sağlamak ve istenmeyen hücreleri yaradan uzak tutma görevinde değillerdir, aynı zamanda yeni kemik oluşumunu da teşvik ederler ${ }^{18}$.

Minimal travma ile diş çekimi yapıldıktan sonra soket tüm yumuşak doku kalıntılarını uzaklaştırmak için dikkatli bir şekilde kürete edilmelidir. Greft yerleştiril-

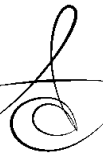


meden önce soketin kanla dolması sağlanmalıdır; çünkü yeterli kemik dolumu için kemikten gelen kanama anahtar rol oynamaktadır. Kan; kemik iyileşmesi için gerekli olan temel proteinleri ve büyüme faktörlerini içermektedir ${ }^{18}$.

Greft, soketin üçte ikilik apikal kısmına çok sıkı olmayacak şekilde yerleştirilmelidir. Soketin fazla doldurulması koronal greft parçalarının sekestrasyonuna neden olur. Kalan üçte birlik kısım gingival dokuların oluşumunu sağlar ${ }^{1}$.

Becker ve ark. ${ }^{27}$ otojen kemik greftleri ile demineralize kuru dondurulmuş kemik allogreftlerini (DFDBA) karşılaştırmışlardır. Çalışma sonucunda, otojen greft konulan bölgelerde üç ay sonra yeni kemik oluşumu görülürken, demineralize kuru dondurulmuş kemik allogreftleri kullanılan bölgelerin yedisinin altısında yeni kemik oluşumu görülmediği ve DFDBA'nın kemik iyileşmesini sekteye uğratabileceği belirtilmiştir.

Artzi ve ark. ${ }^{14}$ sıklıkla kullanılan sığır kemiği greftini 15 çekim soketinde soketi yumuşak doku ile kapatarak kullanmışlardır. 9 ay sonra \%82,3 kemik dolumu olduğunu belirtmişlerdir. Yazarlara göre sığır kemiği grefti, kret korunması için kabul edilebilir biyouyumlulukta bir kemik ürünüdür.

Oltramari ve ark. ${ }^{28}$ domuzlarla yaptıkları çalışmalarında, zenogreftle doldurulmuş çekim soketlerinde, radyografik olarak kemik yoğunluğu ve kemik yüksekliğini incelemişlerdir. Deney grubundaki soketler zenogreftlerle doldurulurken kontrol grubundaki soketler spontan iyileşmeye bırakılmıştır. 3 ay sonra ilgili bölgelerden radyografiler alınarak değerlendirme yapılmıştır. 3 ay sonunda; deney grubunda, belirgin şekilde daha az yükseklik kaybı görüldüğü ve kemik yoğunluğunun daha fazla olduğu belirtilmiştir. Sonuç olarak yazarlar, çekim soketlerinde zenogreft kulanımının başlangıçta kemik yüksekliğini koruduğunu; ama kemik yoğunluğu farkının sürekli olmadığını bildirmişlerdir.

Alkan ve ark. ${ }^{29}$ diş çekimi sonrasında kret korunmasında deproteinize sığır kemiği ve mine matriksi türevi greft materyalini karşılaştırdıkları klinik çalışma sonucunda; her iki materyalin de kret korunması için kullanılabileceğini belirtmiş ve iki materyal arasında belirgin bir farklılık olmadığını bildirmişlerdir.

Nemcovsky ve Serfaty ${ }^{30} 23$ çekim soketinde hidroksiapatit kristalleri kullanmış, flep çevirerek soketi primer kapatmışlar ve 24 ay izlemişlerdir. Sonuçta minimal kret deformasyonuyla birlikte kret korunma- sının iyi olduğunu belirtmişlerdir.

Heberer ve ark. ${ }^{31}$ yaptıkları bir klinik çalışmada çekim soketlerindeki kemik iyileşmelerini greft kullanıp kullanmamalarına göre karşılaştırmışlardır. Çalışma sonucunda Bio-oss kollajen ile greftleme yaptıkları soketlerdeki kemik iyileşmesinin spontan iyileşmeye bırakılan soketlerden daha düşük olduğunu belirtilmiştir.

Guarnieri ve ark. ${ }^{32} 10$ çekim soketine bariyer membran kullanmadan kalsiyum sülfat yerleştirmişler ve 3 ay sonra ilgili bölgeyi tekrar açmışlardır. Çalışma sonucunda kalsiyum sülfatın tamamen rezorbe olduğu ve \%100'lük kemik dolumu görüldüğü bildirilmiştir.

Biyoaktif cam; sentetik, toksik olmayan, biyouyumlu bir materyaldir, aynı zamanda osteogenesisde de pozitif bir rol oynamaktadır. Bu nedenlerden dolayı biyoaktif camın kret korunmasında yardımcı olduğu ortaya çıkmıştır ${ }^{33}$. Camargo ve ark. ${ }^{33} 8$ hastada biyoaktif camla birlikte kalsiyum sülfatı greft materyali olarak kullanmışlar, soketleri biyoaktif camla doldurduktan sonra üstlerini kalsiyum sülfatla kaplamışlardır. 6 ay sonra bölgeyi tekrar açtıklarında kalsiyum sülfat ya da biyoaktif cam kalıntılarıyla karşılaşmamışlar ve soketin sert doku ile dolduğunu görmüşlerdir. Vertikal ve horizontal yönde kemik oluşumunda kontrol grubundan daha iyi sonuçlar verdiği belirtilmiştir. Froum ve ark. ${ }^{34}$ çekim soketlerinde biyoaktif cam kullanmışlar ve demineralize kuru dondurulmuş kemik allogrefti kullanılan soketlerle ve spontan iyileşmeye bırakılan kontrol soketleri ile karşılaştırmıştırlar. Bütün bölgeler flep kaydırılarak kapatılmış, 6-8 ay sonra tekrar açılmıştır. Biyoaktif camın kullanıldığı bölgelerde \%60 oranında kemik vitalitesi görülürken diğer gruplarda bu oran \%33 olarak görülmüştür. Yazarlara göre biyoaktif cam, çekimden sonra soket iyileşmesi için pozitif etkisi olan ostokondüktif bir materyaldir.

Kret korunması için kalsiyum karbonat esaslı alloplastik bir greft materyali de kullanılmaktadır. Bu greft materyali tamamen rezorbe olur ve konakçının kemiğiyle tamamen yer değiştirir. $\mathrm{Bu}$ materyalin granüllerindeki gözeneklerin hacmi; alloplastın rezorpsiyon hızını ve kemik formasyonu hızını etkilemektedir. Fazla boşluk olduğu zaman rezorpsiyon hızı artmaktadır. Bu greft materyali küçük periodontal defektlerden büyük kraniyofasiyal rekonstrüksiyonlara kadar çeşitli boyutlardaki kemik defektlerinde kullanılmaktadırlar ${ }^{35}$. Sandor ve ark ${ }^{35}$. yaptıkları bir çalışmada 21 hastada 17 tanesi anterior bölgede travma sonucu 
kaybedilmiş dişlerin soketinde, 31 tanesi ankiloze posterior dişlerin çekimi sonucu oluşan soketlerin augmentasyonunda kalsiyum karbonat esaslı greft materyalini kullanmışlardır. Greft partikülleri kemikle tamamen yer değiştirmişlerdir; ama anterior bölgede travma sonucu kaybedilmiş dişlerin soketinde geçici olarak kret restorasyonu sağlamışlardır, bu bölgede implant yerleştirilmesi sırasında tekrar ogmentasyon yapılması gerekmiştir. Posterior bölgede ise başarılı olmuştur. Çalışmaya göre, kalsiyum karbonat esaslı greft materyali uygun bölgelerde alvoler kreti rezorpsiyondan korumaktadır ve kemik grefti intiyacını ortadan kaldırmaktadır.

\section{Sadece Membran Kullanımı}

Yumuşak dokunun soket içine girmesini engellemek için çekim soketlerinin membranla örtülmesi de mümkündür ${ }^{1}$. Bunun için rezorbe olan ve olmayan membranlar kullanılmaktadır ${ }^{1,}{ }^{8}$. Rezorbe olabilen membranlara örtülmüş olan kretlerde daha az vertikal kemik kaybı görülmekle birlikte membran kullanımının bazı dezavantajları vardır: i- membranın yumuşak doku ile tamamen kapatılması zordur, membran oral kaviteye açılabilir ve sonuç olarak üstünde bakteri kolonizasyonu oluşabilmektedir ve iimembran greft materyalleri ile desteklenmezse membranın soket içine çökebilmektedir ${ }^{17}$.

Lekovic ve ark. ${ }^{12}$ bir çalışmada çekim sonrası kret devamlıı̆ı̆ı sürdürmek için rezorbe olmayan genişletilmiş politetrafloroetilen (e-PTFE) membranları kullanmışlardır. Soketler kürete edildikten sonra membran ve soketler primer olarak kapatılmıştır. 6 ay sonra bölgeler tekrar açılmıştır. Kontrol grubunda büyük genişlik ve boy kaybı olurken, e-PTFE membranların kullanıldığı çalışma grubunda daha fazla kemik dolumu görülmüştür. Buna rağmen membranların \%30'u ekspoze olmuştur bu da kontrol grubuyla benzer sonuçların elde edilmesine neden olmuştur. Greftlerin ekspoze olma riski yüksek olduğu için yazarlar ePTFE membranların kullanılmaması gerektiğini bildirmişlerdir.

Aynı çalışmacılar daha sonra rezorbe olan membranları kullanarak bir çalışma yapmışlardır. Poliglikolit/laktit membranlar kullanmışlar ve bölgeleri 6 ay sonra tekrar açmışlardır. Membran kullanılan grupta alveoler kemik kaybı belirgin şekilde daha azken, sokette daha fazla kemik dolumu olduğu ve genişlik kaybının yükseklik kaybından daha fazla olduğu görülmüştür. Membranların ekspoze olmama- sının önemli bir sonuç olduğu ve bu nedenle rezorbe olan membranların rezorbe olmayan membranlara göre tercih edilebilir olduğu belirtilmiştir ${ }^{11}$.

\section{Kullanımı}

Kemik Greftleri ve Membranların Birlikte

Bazı çalışmalarda greft ve membran birlikte kullanılmıştır ${ }^{16,36-39}$. Iasella ve ark. $^{38}$ tetrasiklinle sulandırılmış kuru dondurulmuş kemik allogrefti ve rezorbe olabilen membran kullanmışlardır. Soketi tamamen kapatmamışlar ve 4-6 ay sonra bölgeyi tekrar açmışlardır. Her iki grupta da genişlik kaybı olmuştur; ama çalışma grubunda daha az kayıp ve daha fazla kemik dolumu görülmüştür.

Carmagnola ve ark. ${ }^{16}$ deproteinize sığır kemiği partikülleri ile doldurulmuş çekim soketlerinin iyileşmesini araştırmışlardır. Çalışmada 31 soketin 11'inde sadece kollajen membran, 7'sinde membran ve deproteinize sığır kemiğini birlikte kullanmışlar, 10 soketi de spontan iyileşmeye bırakmışlardır. Membran ve greftin birlikte kullanıldığı soketlerin tekrar açıldıkları zaman implant yerleştirilmesi için uygun oldukları görülmüştür. Membran ile örtülen soketlerde bölge 4 ay sonra tekrar açıldığında bol miktarda lamellar kemik ve kemik iliği ve az miktarda süngerimsi kemik görülmüştür.

Norton ve ark. $^{39}$ sığır kemiği minerallerinin osteokondüktivitesini araştırmışlardır. Çalışmada 15 hastada soketler, sığır kemiği ve otojen greftle doldurulmuş ve rezorbe olabilen kollajen membranlarla kapatılmışlardır. Çalışma sonucunda sığır kemiği minerallerinin çekim defektlerinde ve sinüs kavitesinde yeni kemik oluşumunda etkili olduğu belirtilmiştir. Çalışmaya göre sığır kemiği mineralleri, implant yerleştirilmesi öncesinde alveoler defektlerin greftlenmesinde uygun bir materyaldir.

Bifazik kalsiyum fosfat ve kollajen membranın birlikte kullanıldığı bir klinik çalışmada, 4 ay sonunda implantlar yerleştirilirken yapılan değerlendirme sonucunda bifazik kalsiyum fosfatın kollajen membran ile birlikte kullanımının kret korunmasında alternatif olarak kullanılabileceği belirtilmiştir ${ }^{40}$.

Stimmelmayr ve ark. ${ }^{41}$ diş çekimi sonrasında bukkal kemikteki defektlerin tedavisi ve kret korunması için soketlerin bukkal duvarlarını kollajen membranla kaplayıp, soket içini otojen kemik-sığır kemiği karışımı ile doldurduktan sonra soketleri bağ doku grefti ile kapatmışlardır. Çalışma sonucunda; diş çekimi ile aynı seansta bukkal alveoler defektlerin greftlenmesinin ve

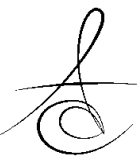


soketin bağ doku grefti ile kapatımasının, umut verici sonuçlar verdiği ve geç dönemde yapılacak sert doku greftlemelerine alternatif bir tedavi seçeneği olabileceği bildirilmiştir.

Çeşitli periodontal ve implant çevresi defektler ile çekim soketi defektlerinin tedavisinde kullanılmak üzere otojen bağ doku greftleri için aselüler dermal matriks allograftı (ADMA) geliştirilmiştir ${ }^{37}$. Aselüler dermal greft cerrahi olarak alınmış ve tüm hücresel materyali ile epidermal tabakası alınmış bir allogrefttir. ADMA; diş ve dental implant çevresindeki yapışık diş eti miktarını arttırmada, diş eti çekilmesi defektlerini tedavi etmede, taze çekim soketlerine yerleştirilen gömülmüş implantları örtmede ve soket korunmasında diş çekimi sonrasında yükseklik ve genişlik kaybının tedavisinde kullanılır ${ }^{1}$. Froum ve ark. ${ }^{37}$ yaptıkları bir çalışmada rezorbe olabilen ADMA ile rezorbe olmayan e-PTFE membranları ve hidroksiapatit (HA) ile inorganik sığır kemiğini (ABB) karşılaştırmışlardır. Çalışmada 8 tane soketi HA ile doldurup yarısını ADMA yarısını da e-PTFE membranlarla kaplamışlardır, diğer 8 soketi de $A B B$ ile doldurup yarısını ADMA diğer yarısını da ePTFE membranlarla örtmüşlerdir. Çekimden 6-8 hafta sonra bölgeler implant yerleştirilmesi için tekrar açılmışlardır. Sonuç olarak, ADMA ile kaplanmış soketlerde $H A$ veya $A B B$ kullanımı fark etmeksizin ePTFE ile kaplanan soketlerden daha fazla kemik oluşumu görüldüğü belirtilmiştir.

Fowler ve $\mathrm{ark}^{36}$. çalışmalarında demineralize kuru dondurulmuş kemik grefti ve aselüler dermal greft kullanmışlardır. Çalışma sonucunda, araştırmacılar doku miktarını implant yerleştirilmesi için uygun bulmuşlardır ve soketin primer kapatılamadığı durumlarda aselüler dermal greftin kullanılabileceğini belirtmişlerdir.

\section{Diğer Materyallerin Kullanımı}

Korunabilecek kadar kemiğin korunabilmesi için sokete bir dolgu materyali koyulması önemlidir; ama bu her zaman kemik grefti mi olmalıdır? Kemik grefti yerine başka dolgu materyalleri de kullanılabilmektedir.

$\mathrm{Bu}$ materyallerden biri absorbe olabilen poliaktit-poliglikolit tampondur. Bu materyal hidrolizis ve hidrolitik mekanizmalarla rezorbe olmaktadır. Yerleştirilen polimerler iyileşme mekanizmasında rol aldıktan sonra normal boşaltım sistemiyle elimine edilen matriks ürünlerine dönüşürler ve komşu dokuyla yer değiştirirler ${ }^{42}$. Serino ve ark. ${ }^{42} 20$ hastada absorbe olabilen poliaktit-poliglikolit tampon kullanmışlardır. Dişler çekildikten sonra soket debride edilmiş, tam kalınıkta flep kaldırımış, rezorbe olabilen tampon yerleştirilmiş ve soket primer kapatımamıştır. 3 ay sonra bölgeler tekrar açıldığında bölgede yoğun osteoblastik aktiviteyle birlikte yeni kemik oluşumu görülmüştür.

Başka bir çalışmada Serino ve ark. ${ }^{17} 36$ hastada absorbe olabilen poliaktit-poliglikolit tampon kullanmışlardır. 6 ay sonra bölgeler tekrar açıldığı zaman tüm soketler kontrol gruplarına göre özellikle, genellikle diş patolojisi nedeniyle kısmen ya da tamamen parçalanmış olarak bulunan orta bukkal bölgede çok az kemik rezopsiyonuyla iyileşmiştirler. Bunun olası nedeninin rezorbe olabilen tamponun, soketi çevreleyen yumuşak dokunun soket içine çökmesini engellemesi olduğu düşünülmüştür. Demineralize kuru dondurulmuş kemik allogrefti, inorganik sığır kemiği veya biyoaktif camın kullanıldığı insan çalışmalarında yerleştirildikten 6-9 ay sonra greft partiküllerinin halen soket içinde olduğu görülmektedir. Poliaktit-poliglikolit tamponun kullanıldığı vakalarda ise materyal parçaları izlenmemektedir. Bunun nedeni olarak, poliaktit-poliglikolit tamponun 50-60 günde rezorbe olabilmesi gösterilmiştir ${ }^{17}$.

Bölükbaşı ve ark. ${ }^{15}$ yaptıkları çalışmada diş çekimi sonrası soketteki rezorptif değişiklikleri önlemek için platelletten zengin plazma (PRP) kullanmışlardır. Hastadan alınan 10 ml'lik kandan elde edilen PRP steril koşullarda kaviteye yerleştirildikten sonra soket duvarları birbirine yaklaştırılarak suturlarla kapatımışır. İşlemden 1 ay sonra bölge tekrar açllarak implant yerleştirilmiştir.

Srisurang ve ark. ${ }^{43}$ domuzlarda yaptıkları deneysel çalışmada çekim soketlerini 4 gruba ayırmış ve soketleri çeşitli materyallerle doldurmuşlardır. Birinci gruptaki soketleri, platelletten zengin fibrin (PRF) ile doldurmuş ve süture etmişlerdir. İkinci grupta soketi serbest palatal greftle kapatmışlar, üçüncü grubu PRF ile doldurup üzerini serbest palatal greftle kapatmışlardır, son grubu ise spontan iyileşmeye bırakmışlardır. 12 hafta sonunda soketler açlıp örnekler alınmıştır. Çalışma sonucunda; PRF'in erken dönem kret korunmasında etkili bir materyal olduğu, serbest palatal greftin tek başına veya PRF ile birlikte herhangi bir etkinliğinin olmadığı belirtilmiştir. 


\section{Kret Koruyucu Olarak İmmediat İmplantların KullanıIması}

İmmediat implant yerleştirilmesi başarılı bir tedavi şeklidir; fakat implantlar yerleştirildikleri sokette kreti koruyamamaktadırlar ${ }^{1}$.

Araujo ve ark. ${ }^{5}$ köpeklerde yaptıkları bir çalışmada immediat implant yerleştirmenin soket duvarlarının rezorpsiyonunu önlemede, özellikle bukkal duvarda, başarısız olduğunu bildirmişlerdir. Bunun nedenini; periodontal ligament liflerinin bağlandığı kemiğin erken kaybı ve flep kaldırımasına bağlı olarak bukkal kemiğin damarsal beslenmesinin kesilmesi olarak açıklamışlardır ${ }^{13}$.

Ferrus ve ark. ${ }^{44}$ yaptıkları bir çalışmada immediat implant yerleştirilmesinin ardından çekim sahasındaki bukkal duvardaki kret değişimlerini incelemişlerdir. Çalışma sonunda yazarlar; çekim soketine immediat implant yerleştirilmesini takiben 4 aylık iyileşme periyodunda; $\mathrm{i}$ - implantın yerleştirildiği saha (anterior/posterior), ii- bukkal kemiğin kalınlığı ve iiihorizontal bukkal boşluğun boyutunun sert doku değişimlerini belirgin olarak etkilediğini belirtmişlerdir. sonrasında oluşan vertikal ve horizontal kret değişikliklerinin minimuma indirilmesinde etkilidir. Kret koruma prosedürlerinde çeşitli oranlarda rezidüel greft materyalleri ve yeni kemik birlikte görülmektedir. Bu oranlar kullanılan teknik ve materyale göre değişmektedir. Bir tekniğin diğerine göre üstünlüğünü gösteren bir kanıt yoktur. Değişik greftleme materyalleri ve değişik iyileşme periyotları çalışmalar arasında karşılaştırma yapmayı zorlaştırmaktadır. Membran kullanımında en iyi tedavi sonuçlarını elde etmek için yumuşak doku kaplaması gerekmektedir. Membranların açığa çıkması istenmeyen sonuçlara neden olabilir. e-PTFE membranların açığa çıkması kollajen membranlardan daha fazla soruna neden olmaktadır. Yaranın primer kapatılması her zaman gerekli değildir. Kret stabilitesi ve implantın uzun dönem başarısı ile ilgili bilgi sınırıdır. Estetik sonuçlarla ilgili bilgi yoktur ve kret korunmasının implant yerleştirilmesini kolaylaştırdığına dair kesin bir kanıt yoktur ${ }^{1,3,11,12,14-}$ $16,29,33,35,37,43,45$

Tablo 1. Kullanılan makalelerin listesi ve tanımlamaları

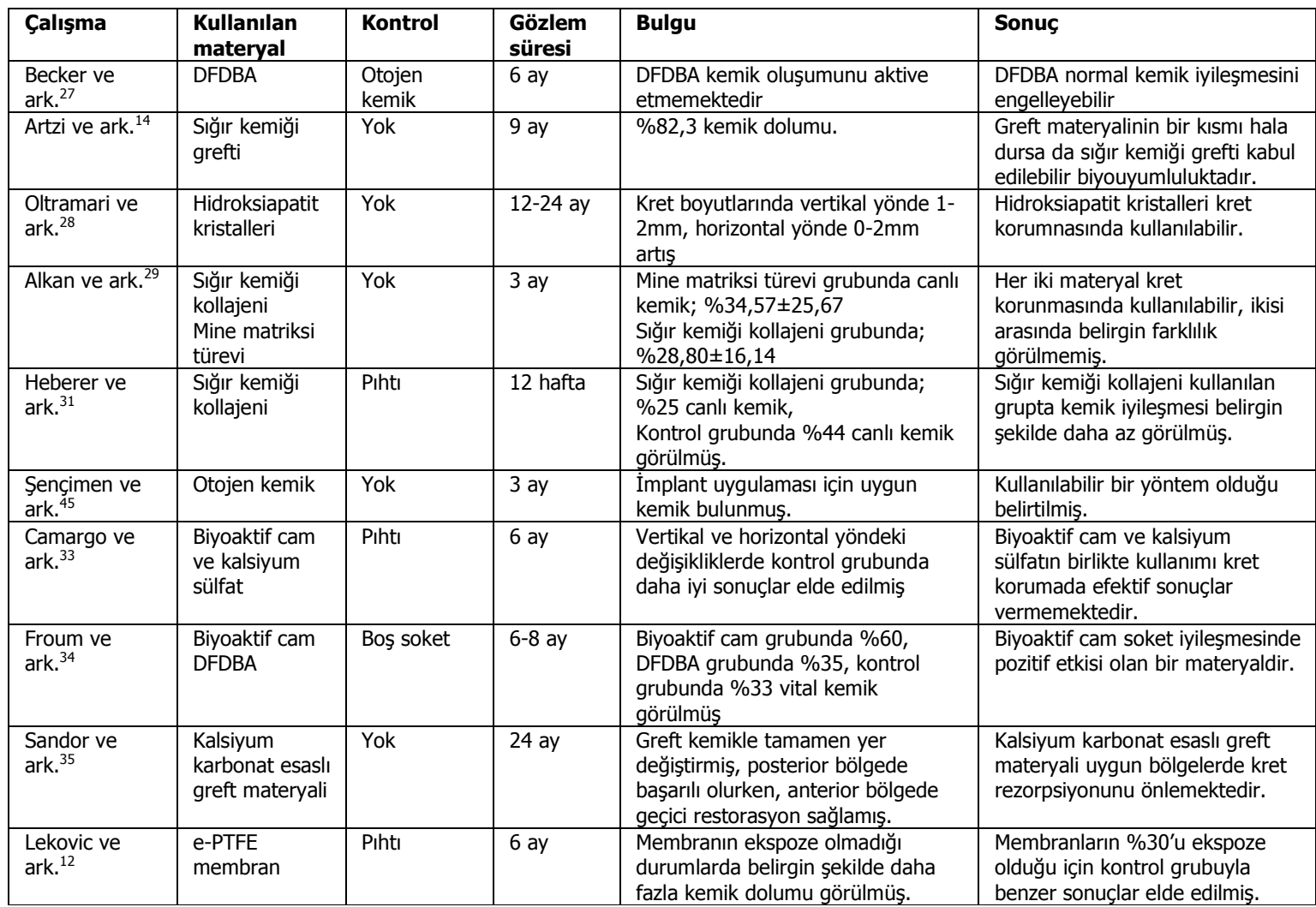




\begin{tabular}{|c|c|c|c|c|c|}
\hline Çalışma & $\begin{array}{c}\text { Kullanılan } \\
\text { materyal }\end{array}$ & Kontrol & $\begin{array}{l}\text { Gözlem } \\
\text { süresi }\end{array}$ & Bulgu & Sonuç \\
\hline Iasella ve ark. ${ }^{38}$ & \begin{tabular}{|c|} 
Kuru \\
dondurulmuş \\
allogreft ve \\
rezorbe olabilen \\
membran \\
\end{tabular} & Pihtı & 4-6 ay & $\begin{array}{l}\text { Horizontal yönde test grubunda - } \\
1,2 \pm 0,9 \mathrm{~mm} \text {, kontrol grubunda - } \\
2,6 \pm 2,3 \mathrm{~mm} \text { kazanım olurken, } \\
\text { vertikal yönde test grubunda daha iyi } \\
\text { sonuçlar elde edilmiş. }\end{array}$ & $\begin{array}{l}\text { Tekniğin kret korumada iyi } \\
\text { sonuçlar verdiği belirtilmiş. }\end{array}$ \\
\hline $\begin{array}{l}\text { Carmagnola ve } \\
\text { ark. }{ }^{16}\end{array}$ & $\begin{array}{c}\text { Rezorbe olabilen } \\
\text { membran } \\
\text { Rezorbe olabilen } \\
\text { membran ve sığırı } \\
\text { kemiğği }\end{array}$ & PIhtı & 4-6 ay & $\begin{array}{l}\text { Sadece membranla kapatılan grupta } \\
\text { lameller kemik ve kemik iliği, } \\
\text { membran ve greft kullanılan grupta } \\
\text { bağ doku ve az miktarda kalan greft } \\
\text { çevresinde kemik, kontrol grubunda } \\
\text { mineralize kemik ve kemik iliği } \\
\text { görülmüş. }\end{array}$ & $\begin{array}{l}\text { Tüm soketler implant } \\
\text { yerleştirilmesi içi uygun } \\
\text { görülmüş. }\end{array}$ \\
\hline Iasella ve ark. ${ }^{38}$ & \begin{tabular}{|c|} 
Kuru \\
dondurulmuş \\
allogreft ve \\
rezorbe olabilen \\
membran
\end{tabular} & PIhtı & 4-6 ay & $\begin{array}{l}\text { Horizontal yönde test grubunda - } \\
1,2 \pm 0,9 \mathrm{~mm} \text {, kontrol grubunda - } \\
2,6 \pm 2,3 \mathrm{~mm} \text { kazanım olurken, } \\
\text { vertikal yönde test grubunda daha iyi } \\
\text { sonuçlar elde edilmiş. }\end{array}$ & $\begin{array}{l}\text { Tekniğin kret korumada iyi } \\
\text { sonuçlar verdiği belirtilmiş. }\end{array}$ \\
\hline $\begin{array}{l}\text { Carmagnola ve } \\
\text { ark. }{ }^{16}\end{array}$ & $\begin{array}{c}\text { Rezorbe olabilen } \\
\text { membran } \\
\text { Rezorbe olabilen } \\
\text { membran ve sığııı } \\
\text { kemiğği }\end{array}$ & Pihtı & 4-6 ay & $\begin{array}{l}\text { Sadece membranla kapatılan grupta } \\
\text { lameller kemik ve kemik iliği, } \\
\text { membran ve greft kullanılan grupta } \\
\text { bağ doku ve az miktarda kalan greft } \\
\text { çevresinde kemik, kontrol grubunda } \\
\text { mineralize kemik ve kemik iliği } \\
\text { görülmüş. }\end{array}$ & $\begin{array}{l}\text { Tüm soketler implant } \\
\text { yerleştirilmesi içi uygun } \\
\text { görülmüş. }\end{array}$ \\
\hline $\begin{array}{l}\text { Carmagnola ve } \\
\text { ark. }^{16}\end{array}$ & $\begin{array}{c}\text { Rezorbe olabilen } \\
\text { membran } \\
\text { Rezorbe olabilen } \\
\text { membran ve sığırı } \\
\text { kemiğği }\end{array}$ & PIhtı & 4-6 ay & $\begin{array}{l}\text { Sadece membranla kapatılan grupta } \\
\text { lameller kemik ve kemik iliği, } \\
\text { membran ve greft kullanılan grupta } \\
\text { bağ doku ve az miktarda kalan greft } \\
\text { çevresinde kemik, kontrol grubunda } \\
\text { mineralize kemik ve kemik iliği } \\
\text { görülmüş. }\end{array}$ & $\begin{array}{l}\text { Tüm soketler implant } \\
\text { yerleştirilmesi içi uygun } \\
\text { görülmüş. }\end{array}$ \\
\hline Lekovic ve ark. $^{11}$ & $\begin{array}{c}\text { Rezorbe olabilen } \\
\text { membran }\end{array}$ & PIhtı & 6 ay & $\begin{array}{l}\text { Membran kullanılan grupta daha az } \\
\text { kemik kaybı görülmüş, horizontal } \\
\text { yönde kaybın vertikal yönde kayıptan } \\
\text { daha fazla olduğu belirtilmiş. }\end{array}$ & $\begin{array}{l}\text { Membranlar ekspoze olmadığı } \\
\text { için rezorbe olmayan } \\
\text { membranlara göre tercih } \\
\text { edilebilir olduğu belirtilmiş. }\end{array}$ \\
\hline $\begin{array}{l}\text { Norton ve } \\
\text { ark. }^{39}\end{array}$ & $\begin{array}{l}\text { Sığır kemiği, } \\
\text { otojen kemik } \\
\text { ve rezorbe } \\
\text { olabilen } \\
\text { membran } \\
\end{array}$ & Yok & $\begin{array}{l}15-44 \\
\text { hafta }\end{array}$ & $\begin{array}{l}\text { Olgunlaşmamış ve lameller kemik } \\
\text { karışımı görülmüş. \%26,9 lameller } \\
\text { kemik, \%25,6 greft, \%47,4 bağ } \\
\text { doku. }\end{array}$ & $\begin{array}{l}\text { Sığır kemiği kret korunması için } \\
\text { uygun bir materyal olduğu } \\
\text { belirtilmiş. }\end{array}$ \\
\hline $\begin{array}{l}\text { Kesmas ve } \\
\text { ark. }^{40}\end{array}$ & $\begin{array}{l}\text { Bifazik } \\
\text { kalsiyum sülfat } \\
\text { ve kollajen } \\
\text { membran } \\
\end{array}$ & Yok & 4 ay & $\begin{array}{l}\text { Greftin yeni kemikle kaynaştığı } \\
\text { görülmüş. }\end{array}$ & $\begin{array}{l}\text { Bifazik kalsiyum sülfat ve } \\
\text { kollajen membranın kret } \\
\text { korunmasında alternatif olarak } \\
\text { kullanılabileceği belirtilmiş. }\end{array}$ \\
\hline $\begin{array}{l}\text { Stimmelmayr } \\
\text { ve ark. }\end{array}$ & $\begin{array}{l}\text { Otojen kemik, } \\
\text { sığır kemiği ve } \\
\text { kollajen } \\
\text { membran }\end{array}$ & Yok & 5,3 ay & $\begin{array}{l}\text { Greft yerleştirildiği sırada kret } \\
\text { genişliği } 6,8 \mathrm{~mm} \text { iken, implant } \\
\text { yerleştirilmesi sırasında 5,65mm } \\
\text { olarak ölçülmüş. }\end{array}$ & $\begin{array}{l}\text { Soketlerin greftle doldurulup } \\
\text { membranla kaplanmasının geç } \\
\text { dönemde yapılacak sert doku } \\
\text { greftlemelerine alternatif } \\
\text { olabileceği belirtilmiş. }\end{array}$ \\
\hline
\end{tabular}


Tablo 1'in devamı

\begin{tabular}{|c|c|c|c|c|c|}
\hline Çalışma & $\begin{array}{c}\begin{array}{c}\text { Kullanılan } \\
\text { materyal }\end{array} \\
\end{array}$ & Kontrol & $\begin{array}{c}\text { Gözlem } \\
\text { süresi }\end{array}$ & Bulgu & Sonuç \\
\hline $\begin{array}{l}\text { Froum ve } \\
\text { ark. }^{37}\end{array}$ & $\begin{array}{l}\text { HA+ADMA } \\
\text { HA+e-PTFE } \\
\text { Siğır } \\
\text { kemiği+ADMA } \\
\text { Sığır } \\
\text { kemiği+e- } \\
\text { PTFE } \\
\end{array}$ & Yok & 6-8 ay & $\begin{array}{l}\text { HA+ADMA; \%34,5 canlı kemik } \\
\text { Sığır kemiği+ADMA; \%41,7 canlı } \\
\text { kemik } \\
\text { HA+e-PTFE; \%27,6 canlı kemik } \\
\text { Sığır kemiği+e-PTFE; \%17,8 canlı } \\
\text { kemik }\end{array}$ & $\begin{array}{l}\text { ADMA kullanılan gruplarda sığır } \\
\text { kemiği ya da hidroksiapatit } \\
\text { kullanımı fark etmeksizin e-PTFE } \\
\text { kullanılan gruplara göre daha iyi } \\
\text { sonuçlar elde edilmiş. }\end{array}$ \\
\hline $\begin{array}{l}\text { Serino ve } \\
\text { ark. }^{42}\end{array}$ & $\begin{array}{l}\text { Poliaktit- } \\
\text { poliglikoit } \\
\text { tampon }\end{array}$ & Pihtı & 3 ay & $\begin{array}{l}\text { Test grubunda ortalama kemik; } \\
\% 59,9 \pm 22,4, \\
\text { Kontrol grubunda ortalama kemik; } \\
\% 48,8 \pm 14,4\end{array}$ & Belirgin bir fark gözlenmemiş. \\
\hline $\begin{array}{l}\text { Serino ve } \\
\text { ark. }^{17}\end{array}$ & $\begin{array}{l}\text { Poliaktit- } \\
\text { poliglikoit } \\
\text { tampon }\end{array}$ & Piht। & 6 ay & $\begin{array}{l}\text { Test grubunda kontrol grubuna } \\
\text { nazaran orta bukkal bölgede daha az } \\
\text { kemik kaybı görülmüş. }\end{array}$ & $\begin{array}{l}\text { Test grubunda daha az } \\
\text { rezorpsiyon görülmüş. }\end{array}$ \\
\hline $\begin{array}{l}\text { Srisurang ve } \\
\text { ark. }^{43}\end{array}$ & $\begin{array}{l}\text { PRF } \\
\text { Palatal greft } \\
\text { PRF ve palatal } \\
\text { greft }\end{array}$ & Piht। & $\begin{array}{l}12 \\
\text { hafta }\end{array}$ & $\begin{array}{l}\text { Kemik yüksekliği; PRF grubunda; } \\
8,96 \mathrm{~mm} \text {, palatal greft gurubunda; } \\
7,99 \mathrm{~mm} \text {, PRF ve palatak greft } \\
\text { grubunda; } 8,37 \mathrm{~mm} \text {, kontrol } \\
\text { grubunda; } 8,40 \mathrm{~mm} \text { olarak } \\
\text { belirlenmiş. }\end{array}$ & $\begin{array}{l}\text { PRF'in erken dönem kret } \\
\text { korunmasında etkili bir materyal } \\
\text { olduğu, palatal greft kullanımının } \\
\text { etkisi olmadığı belirtilmiş. }\end{array}$ \\
\hline
\end{tabular}

\section{KAYNAKLAR}

1. Darby I, Chen S, De Poi R. Ridge preservation: what is it and when should it be considered. Aust Dent J 2008;53:11-21.

2. Buser D, Martin W, Belser UC. Optimizing esthetics for implant restorations in the anterior maxilla: anatomic and surgical considerations. Int J Oral Maxillofac Implants 2004;Suppl 19:43-61.

3. Darby I, Chen ST, Buser D. Ridge preservation techniques for implant therapy. Int J Oral Maxillofac Implants 2009; Suppl 24:260-71.

4. Kan JY, Rungcharassaeng K, Umezu K, Kois JC. Dimensions of peri-implant mucosa: an evaluation of maxillary anterior single implants in humans. J Periodontol 2003;74:557-62.

5. Araujo MG, Sukekava F, Wennstrom JL, Lindhe J. Ridge alterations following implant placement in fresh extraction sockets: an experimental study in the dog. J Clin Periodontol 2005;32:645-52.

6. Schropp L, Wenzel A, Kostopoulos L, Karring T. Bone healing and soft tissue contour changes following single-tooth extraction: a clinical and radiographic 12-month prospective study. Int J Periodontics Restorative Dent 2003;23:313-23.

7. Cardaropoli G, Araujo M, Lindhe J. Dynamics of bone tissue formation in tooth extraction sites. An experimental study in dogs. J Clin Periodontol 2003;30:809-18.
8. Irinakis T. Rationale for socket preservation after extraction of a single-rooted tooth when planning for future implant placement. J Can Dent Assoc 2006;72:917-22.

9. Araujo MG, Lindhe J. Dimensional ridge alterations following tooth extraction. An experimental study in the dog. J Clin Periodontol 2005;32(2):212-8.

10. Pietrokovski J. The bony residual ridge in man. J Prosthet Dent 1975;34:456-62.

11. Lekovic V, Camargo PM, Klokkevold PR, et al. Preservation of alveolar bone in extraction sockets using bioabsorbable membranes. J Periodontol 1998;69:1044-9.

12. Lekovic $V$, Kenney EB, Weinlaender $M$, Han $T$, Klokkevold P, Nedic M, Orsini M. A bone regenerative approach to alveolar ridge maintenance following tooth extraction. Report of 10 cases. J Periodontol. 1997;68:563-70.

13. Araujo MG, Wennstrom JL, Lindhe J. Modeling of the buccal and lingual bone walls of fresh extraction sites following implant installation. Clin Oral Implants Res 2006;17:606-14.

14. Artzi Z, Tal H, Dayan D. Porous bovine bone mineral in healing of human extraction sockets. Part 1: histomorphometric evaluations at 9 months. J Periodontol 2000;71:1015-23.

15. Bölükbaşı N, Mısırlığlu $E$, Havlucu U, Özdemir T. İmplant uygulaması planlanan alanlarda soket 
koruma tekniğinin uygulanması. Oral İmplantoloji Dergisi 2008;9:31-6.

16. Carmagnola $D$, Adriaens $P$, Berglundh T. Healing of human extraction sockets filled with Bio-Oss. Clin Oral Implants Res 2003;14:137-43.

17. Serino G, Biancu S, Iezzi G, Piattelli A. Ridge preservation following tooth extraction using a polylactide and polyglycolide sponge as space filler: a clinical and histological study in humans. Clin Oral Implants Res 2003;14:651-8.

18. Wang HL, Kiyonobu K, Neiva RF. Socket augmentation: rationale and technique. Implant Dent 2004;13:286-96.

19. Marx RE. Bone and bone graft healing. Oral Maxillofac Surg Clin North Am 2007; 19:455-66, v.

20. Scarano A, Piattelli A, Perrotti V, Manzon L, Iezzi G. Maxillary sinus augmentation in humans using cortical porcine bone: a histological and histomorphometrical evaluation after 4 and 6 months. Clin Implant Dent Relat Res 2011;13:138.

21. Katsuyama $H$, Jensen SS. ITI treatment guide: Sinus floor augmentation. Berlin: Quintssence; 2012.

22. Hupp JR, Ellis E, Tucker MR. Contemporary oral and maxillofacial surgery. 5 ed. St. Louis: Mosby; 2008. p. 605-7.

23. Orsini G, Scarano A, Piattelli M, et al. Histologic and ultrastructural analysis of regenerated bone in maxillary sinus augmentation using a porcine bone-derived biomaterial. J Periodontol 2006; 77: 1984-90.

24. Barone A, Crespi R, Aldini NN, et al. Maxillary sinus augmentation: histologic and histomorphometric analysis. Int J Oral Maxillofac Implants 2005; 20:519-25.

25. Pradel W, Eckelt U, Lauer G. Bone regeneration after enucleation of mandibular cysts: comparing autogenous grafts from tissue-engineered bone and iliac bone. Oral Surg Oral Med Oral Pathol Oral Radiol Endod 2006;101:285-90.

26. Xu H, Shimizu Y, Onodera K, Ooya K. Long-term outcome of augmentation of the maxillary sinus using deproteinised bone particles experimental study in rabbits. $\mathrm{Br} \mathrm{J}$ Oral Maxillofac Surg 2005;43:40-5.

27. Becker W, Becker BE, Caffesse R. A comparison of demineralized freeze-dried bone and autologous bone to induce bone formation in human extraction sockets. J Periodontol 1994;65:1128-33.

28. Oltramari PV, Navarro Rde L, Henriques JF, et al. Evaluation of bone height and bone density after tooth extraction: an experimental study in minipigs. Oral Surg Oral Med Oral Pathol Oral Radiol Endod 2007;104:e9-16.

29. Alkan EA, Parlar A, Yildirim B, Senguven B. Histological comparison of healing following tooth extraction with ridge preservation using enamel matrix derivatives versus Bio-Oss Collagen: a pilot study. Int J Oral Maxillofac Surg 2013;42:1522-8.

30. Nemcovsky CE, Serfaty V. Alveolar ridge preservation following extraction of maxillary anterior teeth. Report on 23 consecutive cases. J Periodontol 1996;67:390-5.

31. Heberer S, Al-Chawaf B, Jablonski C, et al. Healing of ungrafted and grafted extraction sockets after 12 weeks: a prospective clinical study. Int J Oral Maxillofac Implants 2011;26:385-92.

32. Guarnieri R, Pecora G, Fini M, et al. Medical grade calcium sulfate hemihydrate in healing of human extraction sockets: clinical and histological observations at 3 months. J Periodontol 2004; 75: 902-8.

33. Camargo PM, Lekovic V, Weinlaender $M$, et al. Influence of bioactive glass on changes in alveolar process dimensions after exodontia. Oral Surg Oral Med Oral Pathol Oral Radiol Endod 2000;90:581-6.

34. Froum S, Cho SC, Rosenberg E, Rohrer M, Tarnow D. Histological comparison of healing extraction sockets implanted with bioactive glass or demineralized freeze-dried bone allograft: a pilot study. J Periodontol 2002;73:94-102.

35. Sandor GK, Kainulainen VT, Queiroz JO, Carmichael RP, Oikarinen KS. Preservation of ridge dimensions following grafting with coral granules of 48 post-traumatic and post-extraction dentoalveolar defects. Dent Traumatol 2003;19:221-7.

36. Fowler EB, Breault L, Rebitski G. Ridge preservation utilising an acellular dermal allograft and demineralised freeze-dried bone allograft: Part 1. A report of 2 cases. J Periodontol 2000; 71: 1353-9.

37. Froum S, Cho SC, Elian N, et al. Extraction sockets and implantation of hydroxyapatites with membrane barriers: a histologic study. Implant Dent 2004;13:153-64. 
38. Iasella JM, Greenwell $H$, Miller $R L$, et al. Ridge preservation with freeze-dried bone allograft and a collagen membrane compared to extraction alone for implant site development: a clinical and histologic study in humans. J Periodontol 2003;74:990-9.

39. Norton MR, Odell EW, Thompson ID, Cook RJ. Efficacy of bovine bone mineral for alveolar augmentation: a human histologic study. Clin Oral Implants Res 2003;14:775-83.

40. Kesmas S, Swasdison S, Yodsanga S, Sessirisombat S, Jansisyanont P. Esthetic alveolar ridge preservation with calcium phosphate and collagen membrane: preliminary report. Oral Surg Oral Med Oral Pathol Oral Radiol Endod 2010;110:e24-36.

41. Stimmelmayr M, Guth JF, Iglhaut G, Beuer F. Preservation of the ridge and sealing of the socket with a combination epithelialised and subepithelial connective tissue graft for management of defects in the buccal bone before insertion of implants: a case series. Br J Oral Maxillofac Surg 2012;50:5505.

42. Serino G, Rao W, Iezzi G, Piattelli A. Polylactide and polyglycolide sponge used in human extraction sockets: bone formation following 3 months after its application. Clin Oral Implants Res 2008;19:2631.

43. Srisurang S, Kantheera B, Narit L, Prisana P. Socket preservation using platelet-rich fibrin in conjunction with epithelialized palatal free graft in minipigs. Journal of Oral and Maxillofac Surg Med and Pathol 2013;108-17

44. Ferrus J, Cecchinato D, Pjetursson EB, et al. Factors influencing ridge alterations following immediate implant placement into extraction sockets. Clin Oral Implants Res 2010;21:22-9.

45. Şençimen M, Gülses A, Varol A, Okçu KM, Bayar GR. Mandibuler simfiz bölgesinden kemik grefti alınmasına yönelik iki basit cerrahi teknik. Atatürk Üniv Dis Hek Fak Derg 2010; Supplement 3:12-6.

\section{Yazışma Adresi}

Yrd. Doç. Dr. Merve ÇAKIR

İstanbul Yeni Yüzyıl Üniversitesi

Diş Hekimliği Fakültesi

Ağız-Diş Çene Cerrahisi Anabilim Dalı İSTANBUL

Tel: 05334550603

e-posta: dtmervecakir@gmail.com 